\title{
Putative role of protein kinase $C$ in neurotoxic inflammation mediated by extracellular heat shock protein 70 after ischemia-reperfusion
}

\author{
Galina Dvoriantchikova ${ }^{1}$, Andrea Rachelle C Santos ${ }^{1}$, Ali M Saeed ${ }^{2}$, Xenia Dvoriantchikova ${ }^{1}$ and Dmitry Ivanov ${ }^{1,3^{*}}$
}

\begin{abstract}
Background: Sterile inflammation occurs in the absence of live pathogens and is an unavoidable consequence of ischemia-reperfusion (IR) injury in the central nervous system (CNS). It is known that toll-like receptor 4 (Tlr4) contributes to damage and sterile inflammation in the CNS mediated by IR. However, the mechanism of TIr4 activation under sterile conditions in ischemic tissue is poorly understood. We performed this study to clarify the mechanism. To this end, we focused on the extracellular heat shock protein 70 (Hsp70), the prototypic Tlr4 ligand.
\end{abstract}

Methods: TIr4-, Myd88- and Trif-knockout animals, as well as C57BL/6 mice, were used for the wild type control. For the in vivo study, we used a mouse model of retinal IR injury. To test the role of protein kinase C (PKC) in IR injury, IR retinas were treated with the PKC inhibitors (polymyxin B and Gö6976) and retinal damage was evaluated by directly counting neurons in the ganglion cell layer of flat-mounted retinas seven days after IR. Primary retinal neurons (retinal ganglion cells) and glial cells were used for in vitro experiments. Quantitative RT-PCR, ELISA and western blot analysis were used to study the production of pro-inflammatory factors in IR retinas and in primary cell cultures.

Results: We found significant accumulation of extracellular Hsp70 in a model of retinal IR injury. We noted that PKC was involved in TIr4 signaling, and found that PKC inhibitors promoted neuroprotection by reducing pro-inflammatory activity in ischemic tissue. To put all of the pieces in the signaling cascade together, we performed an in vitro study. We found that PKC was critical to mediate the Hsp70-dependent pro-inflammatory response. At the same time, the contamination of Hsp70 preparations with low-dose endotoxin was not critical to mediate the production of pro-inflammatory factors. We found that extracellular $\mathrm{Hsp} 70$ can promote neuronal death at least, by mediating production of cytotoxic levels of tumor necrosis factor alpha, predominantly due to the Tlr4/Myd88 signaling cascade.

Conclusions: Our findings suggest that PKC acts as a switch to amplify the pro-inflammatory activity of Hsp70/TIr4 signaling, which is sufficient to mediate neuronal death.

Keywords: Ischemia-reperfusion (IR) injury, Sterile inflammation, Damage-associated molecular patterns (DAMPs), Extracellular heat shock protein 70 (Hsp70), Toll-like receptor 4 (TIr4), Endotoxins, Polymyxin B, Protein kinase C (PKC), Neuronal death

\footnotetext{
*Correspondence: divanov@med.miami.edu

'Bascom Palmer Eye Institute, Department of Ophthalmology, University of

Miami Miller School of Medicine, 1638 NW 10th Ave, Miami, FL 33136, USA

${ }^{3}$ Department of Microbiology and Immunology, University of Miami Miller

School of Medicine, 1600 NW 10th Ave, Miami, FL 33136, USA

Full list of author information is available at the end of the article
} 


\section{Background}

Sterile inflammation, characterized by innate immune responses in tissue, occurs in the absence of live pathogens, is a pathologic hallmark of ischemia-reperfusion (IR) injury in the central nervous system (CNS), and is spatiotemporally related to delayed neuronal death [1-3]. It has been reported that endogenous ligands (damage-associated molecular patterns (DAMPs)) liberated from IR injured cells act through pattern recognition receptors, initiating an innate immune response in tissue [4-9]. Tolllike receptor 4 (Tlr4) is a pattern recognition receptor that initiates an innate immune response in the presence of exogenous (bacteria-derived endotoxins) and endogenous (DAMPs) ligands $[9,10]$. Tlr4 plays a critical role in mediating CNS sterile inflammation and tissue damage triggered by IR $[11,12]$. However, the mechanism by which DAMPs activate Tlr4 was not understood. This issue creates evident challenges for the development of drugs that are effective against IR injury.

Currently, there are conflicting results regarding whether or not DAMPs can directly activate Tlr4. While it was shown that DAMPs or their modifications can directly activate Tlr4 $[3,9,13,14]$, there is evidence that DAMPs can initiate an innate immune response acting in synergy with low-dose endotoxin [15-17]. Since the presence of low endotoxin levels has been reported in many tissues, including the CNS [18-21], it could be possible that DAMPs released after IR combine with endotoxins and cooperate to initiate a pro-inflammatory response that promotes neuronal death and tissue damage. At the same time, many of the studies that argue that DAMPs work with endotoxins use an endotoxin inhibitor named Polymyxin B (PMB) [22]. It is important to note that PMB is also a protein kinase $\mathrm{C}$ (PKC) inhibitor [23-25]. It is known that PKC acts at multiple steps of toll-like receptor signaling, promoting an innate immune response in tissue [26]. Thus, DAMPdependent pro-inflammatory toxicity in ischemic tissue could be due to PKC activity. In this study, we explore whether DAMPs released after IR promote neuronal toxicity alone, because of endotoxin presence, or as a result of PKC activity. To figure out an answer, we focused on the extracellular heat shock protein 70 (Hsp70), the prototypic DAMP molecule and ligand of Tlr4 [3,9,14]. Our findings suggest that Hsp70 released after IR can initiate innate immune-mediated neurotoxicity in a PKC-dependent manner. These findings also propose that the presence of low endotoxin levels in Hsp70 preparations is not critical in mediating the production of pro-inflammatory factors.

\section{Methods}

Materials

All chemicals and reagents were purchased from SigmaAldrich (St. Louis, Missouri, United States, Life Technologies (Grand Island, New York, United States), Thermo Scientific
(Rockford, Illinois, United States) and Lonza (Walkersville, Maryland, United States). Polymyxin B sulfate was purchased from Santa Cruz Biotechnology (Dallas, Texas, United States), recombinant low endotoxin HSP70 (Cat\# ADI-ESP-555-F, < $50 \mathrm{EU} / \mathrm{mg}$ purified protein) was purchased from Enzo Life Sciences (Farmingdale, New York, United States). RAW-BlueTM cells (RAW264.7 macrophages stably transfected with the NF- $\mathrm{KB}$ reporter gene) were purchased from InvivoGen (San Diego, California, United States). Lipopolysaccharides (LPS) from Escherichia coli 0111:B4 were purchased from Sigma-Aldrich (St. Louis, Missouri, United States).

\section{Animals}

All experiments and postsurgical care were performed in compliance with the National Institutes of Health (NIH) Guide for the Care and Use of Laboratory Animals and according to the University of Miami Institutional Animal Care and Use Committee (IACUC) approved protocols. Tlr4-, Myd88-, and Trif-deficient animals (stock numbers 007227; 009088, 005037) and C57BL/6 J (stock number 000664) mice as the wild type (WT) control were obtained from the Jackson Laboratory (Bar Harbor, Maine, United States). Mice were housed under standard conditions of temperature and humidity, with a 12 hour light to dark cycle and free access to food and water. All animals used in our experiments were either 3-month old male mice, or 3 or 12-day old pups.

\section{Transient retinal ischemia}

Anesthesia was induced with isoflurane and maintained for 45 minutes. Anesthetics were administered to the breathing animals through a tightly fitting nose cone. Body temperature was held constant at $37^{\circ} \mathrm{C}$ with a temperaturecontrolled heating pad. After anesthesia, pupils were dilated with $1 \%$ tropicamide to $2.5 \%$ phenylephrine hydrochloride (NutraMax Products Inc., Gloucester, Massachusetts, United States), and corneal analgesia was achieved with one drop of $0.5 \%$ proparacaine $\mathrm{HCl}$ (Bausch and Lomb Pharmaceuticals, Tampa, Florida, United States). Retinal ischemia was induced for 45 minutes by introducing into the anterior chamber of the left eye a 33-gauge needle attached to a normal $(0.9 \% \mathrm{NaCl})$ saline-filled reservoir raised above the animal in order to increase intraocular pressure (IOP, increased to $120 \mathrm{mmHg}$ ). The contralateral eye was cannulated and maintained at normal IOP to serve as a normotensive control. Complete retinal ischemia, evidenced by a whitening of the anterior segment of the eye and blanching of the retinal arteries, was verified by microscopic examination. After the needle was removed, erythromycin ophthalmic ointment (Fera Pharmaceuticals, Locust Valley, New York, United States) was applied to the conjunctival sac. Mice were euthanized by $\mathrm{CO}_{2}$ inhalation under anesthesia. 


\section{Treatment of animals with Polymixin B and Gö6976}

Mice were injected intraperitoneally (IP) with either PMB (8 $\mu \mathrm{g} / \mathrm{g}$ body of mouse) or Gö6976 (167 ng/g body of mouse it is fine to leave as is) one hour before ischemia, six hours after surgery, and twice every twenty four hours until they were euthanized. Control animals were treated with phosphate-buffered saline (PBS). To evaluate the real concentration of PMB and Gö6976 in the retina, we performed the following calculations. After the IP injection, the drug was distributed throughout the animal's body and accumulated in the tissues and organs. Thus, we had to take into account the volume of the whole animal body in our calculations. The average volume of the adult mice used in our study was $30 \mathrm{ml}$ (we used Archimedes' principle to measure this volume, by immersing the body of the mouse in water and measuring volume of water displacement, which equals volume of the mouse's body)). To calculate the PMB concentration, we took into account: 1) mouse volume $=30 \mathrm{ml}$; 2) $\mathrm{PMB}$ molecular weight $=1301.56 \mathrm{~g} / \mathrm{mol}$; 3) we injected $8 \mu \mathrm{g}$ of PMB per $1 \mathrm{~g}$ of mouse; 4 ) average mouse weight = $30 \mathrm{~g}$. Thus, we injected a total of $240 \mu \mathrm{g}$ of PMB per one injection $(30(\mathrm{~g}) \times 8(\mu \mathrm{g}$ of $\mathrm{PMB}$ per $1 \mathrm{~g}$ of mouse $)=$ $240 \mu \mathrm{g})$. We injected $240 \times 10^{-6}(\mathrm{~g}$ of $\mathrm{PMB}) / 1301.56$ $(\mathrm{g} / \mathrm{mol})=1.84 \times 10^{-7} \mathrm{~mol}$. Therefore, the concentration was $1.84 \times 10^{-7}(\mathrm{~mol}) /\left(30 \times 10^{-3} \mathrm{~L}\right)=6.1 \times 10^{-6}(\mathrm{~mol} / \mathrm{L})=$ $6 \mu \mathrm{M}$. However, we took into account that the total water content of the mouse was about $80 \%$, and so the final concentration was $7.5 \mu \mathrm{M}$. By performing similar calculations and considering that Gö6976's molecular weight was $378.43 \mathrm{~g} / \mathrm{mol}$, we calculated the final concentration of Gö6976, which was equal to $551 \mathrm{nM}$. Importantly, since mice were injected intraperitoneally (IP) twice every twenty four hours until they were euthanized seven days later (after reperfusion), the real concentration of PMB and Gö6976 in the retina could be higher.

\section{Immunohistochemistry}

Eyes were enucleated upon euthanasia, incised at the ora serrate, and immersion-fixed in 4\% PF. After one hour, the retinas were removed and cryoprotected overnight in $30 \%$ sucrose. The following day, the retinas underwent three freeze-thaw cycles, were rinsed $3 \times 10$ minutes in $0.1 \mathrm{M}$ Tris buffer, were blocked by $5 \%$ donkey serum and $0.1 \%$ Triton X-100 in 0.1 M Tris buffer for one hour, and were then incubated overnight with either monoclonal FITC-conjugated neuronal nuclei (NeuN) antibody (1:300; Chemicon, Billerica, Massachusetts, United States) or beta III Tubulin antibody (1:250; Covance, Denver, Pennsylvania, United States). After $3 \times 10$ minutes rinsing in $0.1 \mathrm{M}$ Tris buffer, the retinas were flat-mounted, cover-slipped, and imaged using a Leica TSL AOBS SP5 confocal microscope (Leica Microsystems, Exton, Pennsylvania, United States).

\section{Counting of ganglion cell layer neurons}

NeuN- or beta III Tubulin-positive neurons in the ganglion cell layer (GCL) were imaged by confocal microscopy in flat-mounted retinas. Individual retinas were sampled randomly to collect a total of 20 images from four retinal quadrants using a $20 \times$ objective lens. Five images were collected from each quadrant: one from the center, two from the middle, and two from the peripheral regions of the retina. NeuN-positive neurons were counted using Image software. This software counts cells semi-automatically, meaning that it records the number of cells that are clicked on by the person identifying cells in the image. Cell loss in the ischemic retinas was calculated as a percentage of the mean cell density in normotensive fellow control eyes.

\section{NF-KB reporter assay}

RAW-Blue cells (RAW264.7 macrophages stably expressed a secreted embryonic alkaline phosphatase gene inducible by NF- $\mathrm{kB}$ and resistant to the selectable marker Zeocin) were seeded in 96-well plates in test medium (DMEM, $4.5 \mathrm{~g} / \mathrm{l}$ glucose, $10 \%$ heat-inactivated FBS, $100 \mathrm{mg} / \mathrm{ml}$ Normocin $^{\mathrm{TM}}, 2 \mathrm{mM}$ L-glutamine) at a density of $4 \times 10^{5}$ cells $/ \mathrm{ml}$ and grown overnight in a $5 \% \mathrm{CO}_{2}$ incubator at $37^{\circ} \mathrm{C}$. After treated as indicated, the medium was harvested, and 20- $\mu$ l samples were mixed with the QUANTIBlue $^{\mathrm{Tm}}$ (InvivoGen, San Diego, California, United States) medium $(200 \mu \mathrm{l})$ in 96 -well plates at $37^{\circ} \mathrm{C}$ for 15 minutes, and the optical density at $655 \mathrm{~nm}$ was measured on a Multiskan microplate spectrophotometer (Thermo Scientific, Brookfield, Wisconsin, United States).

\section{Primary cultures of retinal ganglion cells, astrocytes and microglia}

To isolate retinal ganglion cells (RGCs), we used the twostep immunopanning protocol $[8,27]$. To this end, the retinas were incubated in papain solution $(16.5 \mathrm{U} / \mathrm{mL})$ for 30 minutes. Next, macrophage and endothelial cells were removed from the cell suspension by panning with the anti-macrophage antiserum (Accurate Chemical, Westbury, New York, United States). RGCs were bound to the panning plates containing anti-Thy1.2 antibody and released by trypsin incubation. Isolated primary RGCs were grown in serum-free media (Neurobasal/B27 media; Life Technologies, Grand Island, New York, United States) one day before the experiment. Astrocytes and microglial cells were obtained by the 'shaking method' as previously described [28]. These cells were cultured in DMEM (Life Technologies, Grand Island, New York, United States) containing 10\% heat-inactivated fetal bovine serum (FBS) (Life Technologies, Grand Island, New York, United States) one day before the experiment. Astrocytes and microglial cells were maintained during the experiment in DMEM containing $0.1 \%$ FBS. To prepare RGC/glia co-culture, 
RGCs were plated on cover slips in 24-well plate. Glia were plated in culture inserts and placed into the culture wells containing RGCs 24 hours prior to treatment. RGC/glia cocultures containing $0.1 \%$ FBS were maintained during the experiment in DMEM.

\section{Neuronal death assay}

After treatment, dead neurons were determined using a kit (Vybrant Apoptosis Assay Kit \#2; Life Technologies, Grand Island, New York, United States). Cells were imaged using a confocal microscope (Leica TSL AOBS SP5; Leica Microsystems, Pennsylvania, United States). Individual glasses were sampled randomly to collect a total of 10 images using a $20 \mathrm{X}$ objective lens. The dead RGCs were counted using ImageJ software. The percentage of dead RGCs relative to the total number of cells was determined. The experiment was repeated at least three times.

\section{Quantitative reverse transcription polymerase chain reaction (RT-PCR) analysis}

To perform quantitative RT-PCR analysis using genespecific primers (Table 1), total RNA was extracted from retinas and primary cell cultures using Absolutely RNA Nanoprep or Microprep kits (Agilent Technologies, Santa Clara, California, United States) and reverse transcribed with the Reverse Transcription System (Promega, Madison, Wisconsin, United States) to synthesize cDNA. Quantitative PCR was performed in the Rotor-Gene Q Cycler (Qiagen, Valencia, California, United States) using the SYBR GREEN PCR MasterMix (Qiagen, Valencia, California, United States). For each gene, relative expression was calculated by comparison with a standard curve, following normalization to the housekeeping gene $\beta$-actin (Actb) and succinate dehydrogenase subunit A (Sdha) expression chosen as controls.

\section{Western blot analysis}

Astrocyte monolayers were lysed with RIPA (named after its original application, radio-immunoprecipitation assay) buffer supplemented with complete protease inhibitor (Roche Applied Science, Indianapolis, Indiana, United States). Protein concentration was assessed using the BCA kit (Thermo Scientific, Brookfield, Wisconsin, United States). An equal amount of total protein from each sample was resolved on SDS-PAGE gradient gels and transferred to PVDF (polyvinylidene fluoride) membrane (Life Technologies, Grand Island, New York, United States). Blots were blocked in 5\% milk in Tris-buffered saline (TBS, pH 7.6), probed with the primary antibody against Il1b (1:1,000, Abcam, Cambridge, Massachusetts, United States) overnight, washed in $0.15 \%$ Tween 20 in TBS, and incubated for one hour with secondary antibody (1:10,000, Amersham Biosciences, New Jersey, United States) diluted in TBS. Anti- $\beta$-actin antibodies were used to control the
Table 1 List of PCR primers

\begin{tabular}{|c|c|c|}
\hline \multirow{2}{*}{$\frac{\text { Gene }}{\text { Myd88 }}$} & \multicolumn{2}{|c|}{ Oligonucleotides } \\
\hline & Forward & CTTGATGACCCCCTAGGACA \\
\hline & Reverse & AGGCTGAGTGCAAACTTGGT \\
\hline \multirow[t]{2}{*}{ Trif } & Forward & AGACCCCTACAGCCAGGTCT \\
\hline & Reverse & GGCATGGAGAAGCTTTGACT \\
\hline \multirow[t]{2}{*}{ Ripk1 } & Forward & TGATGCACGTGCTAAAGACC \\
\hline & Reverse & TGTTCGGGTGCCATGTAGTA \\
\hline \multirow[t]{2}{*}{$\| 16$} & Forward & GACCTTCCAGGATGAGGACA \\
\hline & Reverse & AGGCCACAGGTATTTTGTCG \\
\hline \multirow[t]{2}{*}{ Tnf } & Forward & CAAAATTCGAGTGACAAGCCTG \\
\hline & Reverse & GAGATCCATGCCGTTGGC \\
\hline \multirow[t]{2}{*}{$\mathrm{Ccl} 2$} & Forward & AGGTCCCTGTCATGCTTCTG \\
\hline & Reverse & ATTTGGTCCGATCCAGGTT \\
\hline \multirow[t]{2}{*}{$\mathrm{Ccl5}$} & Forward & AGCAGCAAGTGCTCCAATCT \\
\hline & Reverse & ATTTCTTGGGTTGGTGTGC \\
\hline \multirow[t]{2}{*}{ Cxcl10 } & Forward & GCTGCAACTGCATCCATATC \\
\hline & Reverse & CACTGGGTAAAGGGGAGTGA \\
\hline \multirow[t]{2}{*}{ Icam1 } & Forward & TGGTGATGCTCAGGTATCCA \\
\hline & Reverse & CACACTCTCCGGAAACGAAT \\
\hline \multirow[t]{2}{*}{ Ncf1 } & Forward & CGAGAAGAGTTCGGGAACAG \\
\hline & Reverse & AGCCATCCAGGAGCTTATGA \\
\hline \multirow[t]{2}{*}{ Nox2 } & Forward & GACTGCGGAGAGTTTGGAAG \\
\hline & Reverse & ACTGTCCCACCTCCATCTTG \\
\hline \multirow[t]{2}{*}{ Nos2 } & Forward & CAGAGGACCCAGAGACAAGC \\
\hline & Reverse & TGCTGAAACATTTCCTGTGC \\
\hline \multirow[t]{2}{*}{ Sdha } & Forward & ACACAGACCTGGTGGAGACC \\
\hline & Reverse & GCACAGTCAGCCTCATTCAA \\
\hline \multirow[t]{2}{*}{ Actb } & Forward & САCCCTGTGCTGCTCACC \\
\hline & Reverse & GCACGATTTCCCTCTCAG \\
\hline
\end{tabular}

loading. Proteins were visualized using SuperSignal chemiluminescent substrates (Thermo Scientific, Brookfield, Wisconsin, United States) and quantified using the FUJIFILM software (Fujifilm, www.fujifilm.com).

\section{Enzyme-linked immunosorbent assay (ELISA)}

The amount of Tnf and Il1b in culture media was determined by using mouse Tnf-specific, and mouse Il1bspecific ELISA kits (eBioscience, San Diego, California, United States) according to the manufacturer's protocols. The amount of Hsp70 in the vitreous humor was measured by using a mouse Hsp70-specific ELISA kit (Enzo Life Sciences, Farmingdale, New York, United States). The determination of the protein levels was performed according to the manufacturer's protocols.

\section{Measurement of Hsp70 levels in the vitreous humor} It is known that the volume of vitreous humor in the mouse eye is $5.3 \mu \mathrm{l}$ [29]. To collect the vitreous humor $(\mathrm{VH})$, the 
sclera was penetrated by using a 33-gauge needle at a point temporal and posterior to the limbus, behind the lens. A small drop of $\mathrm{VH}$ that drained out was collected. This collected volume was equal to $2.5 \mu \mathrm{l}$, which was transferred in the tube containing $22.5 \mu \mathrm{l}$ of PBS. Thus, the $\mathrm{VH}$ content was diluted tenfold. The tube was centrifuged at $1100 \mathrm{RPM}$ for 15 minutes at $+4^{\circ} \mathrm{C}$ and the supernatant was collected. To evaluate the Hsp70 level, ten microliters of the supernatant were added to $90 \mu \mathrm{l}$ of ELISA buffer and the $100 \mu \mathrm{l}$ were used for ELISA analysis. Therefore, the VH content was diluted tenfold a second time and the final dilution factor was 100 . The measured Hsp70 levels were multiplied by 100 , which gave us the final concentrations. To evaluate Hsp70 concentration in the GCL, we made the following assumptions: 1) GCL thickness is $30 \mu \mathrm{m}$, retinal area is $15.6 \mathrm{~mm}^{2}$ [29], so the GCL volume $\left(\mathrm{V}_{\mathrm{GCL}}\right)$ was $468^{* 1} 10^{-6} \mathrm{ml}$; 2 ) only half of Hsp70 proteins released after IR are diffused in VH from GCL; 3) efficiency of Hsp70 penetration from the GCL to the $\mathrm{VH}$ due to the inner limiting membrane (the border between the $\mathrm{VH}$ and the retina) is 10 to $50 \%(1 / 10 \div 1 / 2)$.

\section{Intravitreal injection}

Intravitreal injections were performed under a microsurgical microscope using glass pipettes with a diameter of approximately $150 \mu \mathrm{m}$ at the tip. The left eye was punctured at the upper nasal limbus and a volume of $1 \mu \mathrm{l}$ of Hsp70 (1 $\mu$ g per injection) was injected. The contralateral eye was injected with a vehicle (control). To allow the solution to diffuse, the pipette was kept in place for about 15 seconds.

\section{Detection of endotoxins}

All equipment, glassware, and materials used in the following procedures were either purchased as endotoxinfree or had been made endotoxin-free by heating at $250^{\circ} \mathrm{C}$ for 30 minutes. We took into account that the mean retinal thickness is $210 \mu \mathrm{m}$ and retinal area is $15.6 \mathrm{~mm}^{2}$ [29]. Thus, retinal volume $\left(\mathrm{V}_{\mathrm{r}}\right)$ was $3.276 \mu \mathrm{l}$. To measure endotoxin levels, $84 \mu \mathrm{l}$ of endotoxin-free water was added to 20 retinas $(66 \mu \mathrm{l})$. Then, three cycles of freezing in a liquid nitrogen bath and thawing in a $100^{\circ} \mathrm{C}$ water bath, followed by vortexing until tissue had dissolved as much as possible, were performed. The resulting tissue homogenates were centrifuged for 15 minutes at maximum speed and supernatants were collected. In order to evaluate the endotoxin level, $100 \mu$ of the supernatant were used to measure the endotoxin by using the PYROGENT $^{\mathrm{mx}}$ Ultra Gel Clot LAL $(0.03 \mathrm{EU} / \mathrm{ml}$ sensitivity) assay, as recommended by the manufacturer (Lonza, Walkersville, Maryland, United States). To prepare serum, the blood was collected from the heart and allowed to clot by leaving it undisturbed at room temperature (30 to 60 minutes). The clot was removed by centrifuging at maximum speed for 15 minutes in a refrigerated centrifuge. The resulting supernatant (serum) was transferred into new endotoxin-free tubes and frozen at $-80^{\circ} \mathrm{C}$. All culture media were processed using a sterile technique and stored at $-80^{\circ} \mathrm{C}$ prior to assays. The PYROGENT ${ }^{\mathrm{mm}}$ Ultra Gel Clot LAL (0.03 EU/ml sensitivity) assay was performed as recommended by the manufacturer (Lonza, Walkersville, Maryland, United States). To determine the endotoxin concentration, we tested serial two-fold dilutions of samples until an endpoint was reached.

\section{Statistical analysis}

Statistical analysis was performed with a one-way analysis of variance (ANOVA) followed by the Tukey test for multiple comparisons. In the case of single comparisons, the Student's t-test was applied. $P$ values equal to or less than 0.05 were considered statistically significant.

\section{Results}

Polymyxin B mediates neuroprotection after ischemiareperfusion injury due to protein kinase $C$ inhibition rather than endotoxin inhibition

Necrosis is a pathologic hallmark of IR injury in the CNS [4-7]. Retinal IR injury results in a prolonged period of cell death with a high level of necrosis at the early stage of pathology $[4,5,30]$. We have previously demonstrated that the release of DAMPs, as a result of retinal necrosis and Tlr4 signaling, contributes to IRinduced retinal injury $[5,8,11]$. Thus, the retinal ischemia model was the most suitable model to achieve the objectives of this study. We first asked whether endotoxins play a role in IR-induced retinal injury. To answer this question, we used PMB, a known inhibitor of endotoxin activity [22]. Mice were injected IP with PMB $(8 \mu \mathrm{g} / \mathrm{g}$ body of mouse or $7.5 \mu \mathrm{M}$ ) or PBS (control) one hour before IR, six hours after surgery, and twice every twenty four hours until they were euthanized seven days later, after reperfusion. Whole retina flat-mounts were stained for the neuronal marker NeuN to quantify the number of surviving neurons in the GCL. We found that retinas from the experimental eyes of PBS-treated mice had significantly lower numbers of surviving NeuN-positive neurons in the GCL compared to PMB-treated mice (51 $\pm 5 \%$ versus $87 \pm 4 \%, P<0.01$ ) (Figure 1 ). To evaluate the molecular changes associated with resistance to IR injury in PMB-treated retinas, we investigated the activation of several pro-inflammatory markers known to be involved in IR-induced cytotoxicity. We compared gene expression in ischemic versus sham-operated eyes for both PBS- and PMB-treated mice. We found transcriptional up-regulation of cytokines (Tnf, Illb), chemokines (Ccl2, Ccl5, and Cxcl10), cell adhesion molecule (Icam1), as well as genes encoding subunits of the reactive oxygen species-producing $\mathrm{NAD}(\mathrm{P}) \mathrm{H}$ oxidase, in all experimental eyes at both 6 and 

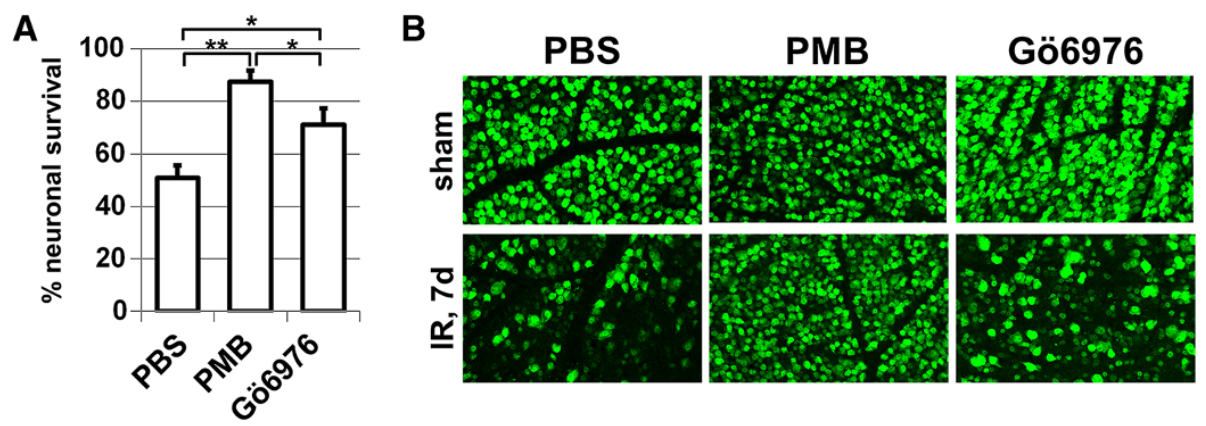

Figure 1 Treatment with PMB and Gö6976 results in neuroprotective effects in the GCL after IR: A) Percentage of GCL neurons lost at one week following IR of C57bl/6 mice treated with PMB, Gö6976, and PBS (control) (**P<0.01, ${ }^{*} P<0.05, n=5-7$ ). B) Representative confocal images of NeuN-labeled GCL (green) neurons in flat-mounted retinas in sham-operated controls and ischemic retinas 7 days after reperfusion. GCL, ganglion cell layer; IR, ischemia reperfusion; NeuN, neuronal nuclei; PBS, phosphate buffered saline; PMB, polymyxin B.

12 hours after reperfusion (Figure 2). In PMB-treated mice, however, the expression of Thf, Il1b, Ccl2, Cxcl10, Icam1, $C c l 2, C x c l 10$, and subunits of $\mathrm{NAD}(\mathrm{P}) \mathrm{H}$ oxidase $C y b b$ (Nox2) and Ncf2 was reduced relative to PBS-treated mice (Figure 2). One interpretation of these data is that PMB promotes neuroprotection by reducing pro-inflammatory activity in ischemic tissue.

The next step in our study was to detect endotoxin levels in the retina. To evaluate the endotoxin levels in the retina, we used a gel clot LAL assay kit with sensitivity of $0.03 \mathrm{EU} / \mathrm{ml}$ (since $1 \mathrm{EU}=100 \mathrm{pg}$, then $0.03 \mathrm{EU} / \mathrm{ml}=3$ $\mathrm{pg} / \mathrm{ml})$. We collected and analyzed endotoxin levels in three groups containing 20 retinas each. Surprisingly, we did not detect a positive reaction for any of the three groups using the gel clot LAL assay. Since the presence of endotoxins in the blood can affect endotoxin levels in the retina after IR due to blood-retinal barrier breakdown, we also attempted to determine the level of endotoxins in serum, but did not find detectable levels of circulating endotoxins. Given that PMB functions by inhibiting endotoxins and the fact that we did not detect endotoxins, these data suggested that the observed PMB effect in ischemic tissue was probably not due to endotoxin presence. To explain the PMB effect in absence of endotoxins, we noted that PMB is also a PKC inhibitor (IC50, 2-10 $\mu \mathrm{M})$ [23-25]. Our calculations, presented in the 'Methods' section, indicated that the concentration of PMB in the retina was at least $7.5 \mu \mathrm{M}$. Thus, we asked whether or not PMB's neuroprotection could be due to PKC inhibition in ischemic tissue. To test this hypothesis, we used a PKC inhibitor (Gö6976), which selectively inhibits $\mathrm{Ca}^{2+}$-dependent PKC isozymes similar to PMB. The animals were treated with Gö6976 (167 ng/g body of mouse or $551 \mathrm{nM}$ ) IP one hour before ischemia, six hours after surgery, and twice every twenty four hours until they were euthanized. Control animals were treated with PBS. After seven days, the retinas were collected and stained for the neuronal marker NeuN, and the percentage of surviving
GCL neurons was revealed. We found that the percentage of surviving GCL neurons in the IR retinas was significantly higher in mice injected with Gö6976 (71 $\pm 6 \%)$ compared with those injected with PBS $(51 \pm 5 \%, P<0.05)$ (Figure 1). Collectively, these data suggest that perhaps the observed PMB-induced protection was due to PKC inhibition, rather than its endotoxin inhibiting function.

\section{Presence of protein kinase $C$ but not endotoxins critical} to mediate Hsp70-dependent pro-inflammatory response To study in detail the observed effects in our model, we needed to identify Tlr4 ligands, which can initiate a proinflammatory response. Since Hsp70 is a Tlr4 ligand that can stimulate Tlr4 downstream pro-inflammatory effects, we tested whether Hsp70 is released in the extracellular space after IR injury. We measured Hsp70 levels in the $\mathrm{VH}$ of the eye 6 and 24 hours after IR injury in the retina by using the mouse Hsp70-specific ELISA kit (Figure 3). We observed an increase in Hsp70 protein content in the $\mathrm{VH}$ of ischemic eyes 6 hours $(78 \pm 17 \mathrm{ng} / \mathrm{ml})$ and 24 hours $(45 \pm 13 \mathrm{ng} / \mathrm{ml})$ after reperfusion compared to shamoperated controls $(0 \pm 0 \mathrm{ng} / \mathrm{ml}$ and $2 \pm 2 \mathrm{ng} / \mathrm{ml})$. Thus, our data indicated that Hsp70 concentration in the $\mathrm{VH}$ of ischemic eyes was in the range of 50 to $100 \mathrm{ng} / \mathrm{ml}$. Since $\mathrm{VH}$ volume is approximately $5.3 \mu \mathrm{l}$ in mice [29], the quantity of Hsp70 in the $\mathrm{VH}$ is estimated to be 265 to $530 \mathrm{pg}$. Since only half of Hsp70 proteins are diffused in the VH from the GCL, the GCL may contain 530 to $1060 \mathrm{pg}$ of Hsp70. However, since there is the inner limiting membrane between the $\mathrm{VH}$ and the GCL that poses a barrier for penetration of $\mathrm{Hsp} 70$ into the $\mathrm{VH}$ from the GCL, the actual quantity of the extracellular Hsp70 in the GCL should be in the range of 1-10 ng (Methods). Since GCL volume is $468^{*} 10^{-6} \mathrm{ml}$ (Methods), the real concentration of Hsp70 in GCL after IR should be in the range of $2 \div 20 \mu \mathrm{g} / \mathrm{ml}$. Based on these data, we evaluated the minimum concentration of $\mathrm{Hsp} 70$ required to initiate a pro-inflammatory response. To figure this out, 

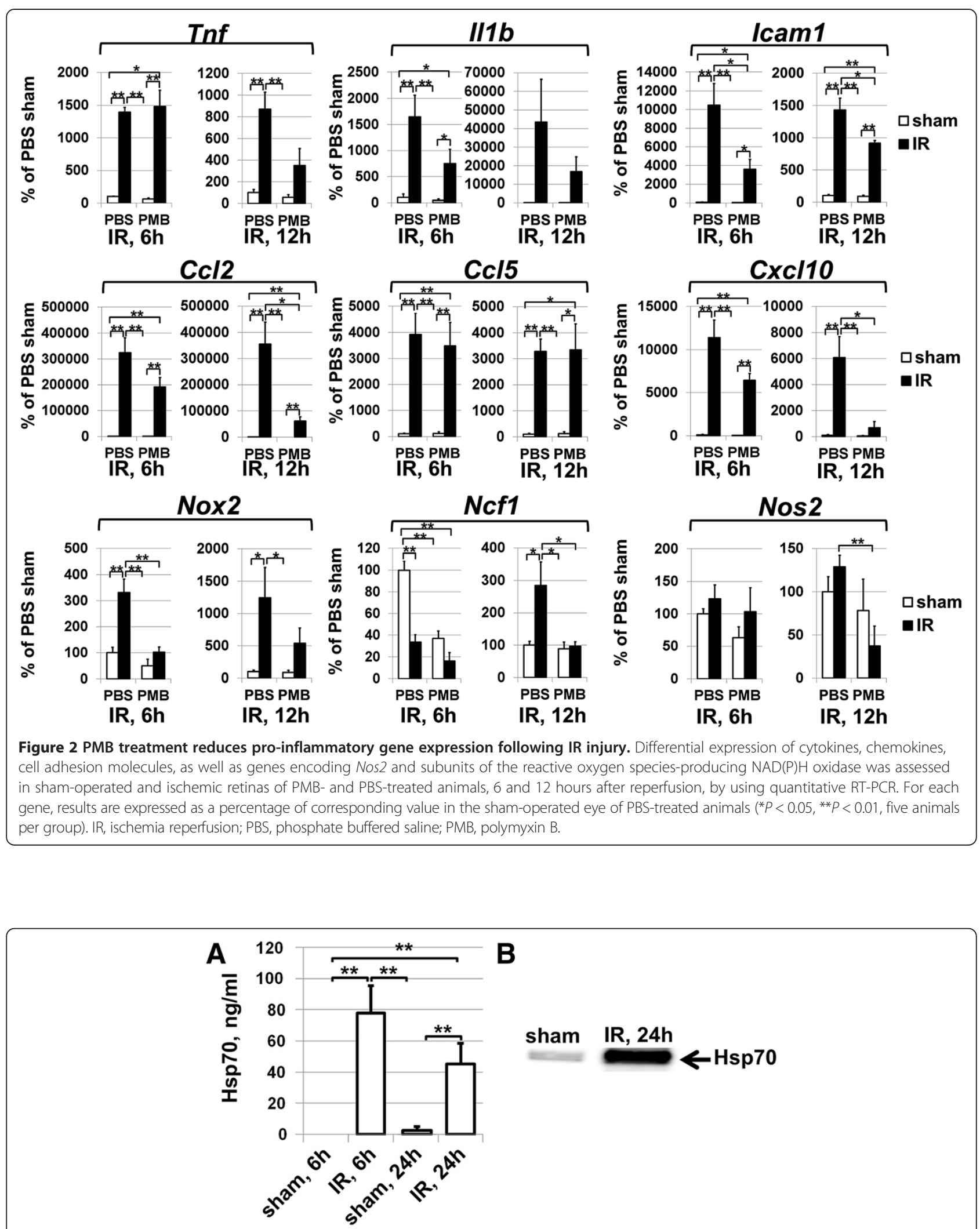

Figure 3 Extracellular Hsp70 is accumulated in the vitreous humor of animals suffering from retinal ischemia: A) Level of Hsp70 in vitreous humor of sham-operated and ischemic eyes 6 and 24 hours after reperfusion. B) Representative western blot. h, hours; Hsp70, heat shock protein 70; IR, ischemic reperfusion. 
we used a mouse macrophage RAW-blue reporter cell line which, upon Tlr4 stimulation, initiates NF-kB-dependent production and secretion of easily detectable and measurable embryonic alkaline phosphatase (SEAP). The RAWblue cells were treated with recombinant Hsp70 protein. When we first measured endotoxin levels in culture media containing the recombinant Hsp70, we found that $10 \mu \mathrm{g} / \mathrm{ml}$ of Hsp70 contains $3 \mathrm{pg} / \mathrm{ml}(0.03 \mathrm{EU} / \mathrm{ml})$ of endotoxins. Measuring the level of SEAP in the media of Hsp70 treated RAW-blue cells, we have detected that the combination of $5 \mu \mathrm{g} / \mathrm{ml}$ of $\mathrm{Hsp} 70$ and $1.5 \mathrm{pg} / \mathrm{ml}(0.015 \mathrm{EU} / \mathrm{ml})$ of endotoxins is enough to activate NF- $\mathrm{kB}$ (Figure 4). We also found that heat inactivation of $\mathrm{Hsp} 70$ significantly reduced SEAP production in RAW-blue cells.

Next, we investigated the Hsp70-dependent proinflammatory response of glial cells, because their activation was shown to occur temporally before leukocyte infiltration in ischemic retina. Glial cells (astrocytes and microglia) were isolated from WT and Tlr4 knockout animals (Tlr4KO) and treated for 24 hours with $5 \mu \mathrm{g} / \mathrm{ml}$ of Hsp70 containing $1.5 \mathrm{pg} / \mathrm{ml}(0.015 \mathrm{EU} / \mathrm{ml})$ of endotoxins. We observed increased levels of cytokine, chemokine, $\mathrm{NAD}(\mathrm{P}) \mathrm{H}$ oxidase, and nitric oxide synthase activity in Hsp70-treated glial cells compared to the PBS-treated control (Figure 5). This activity was significantly reduced

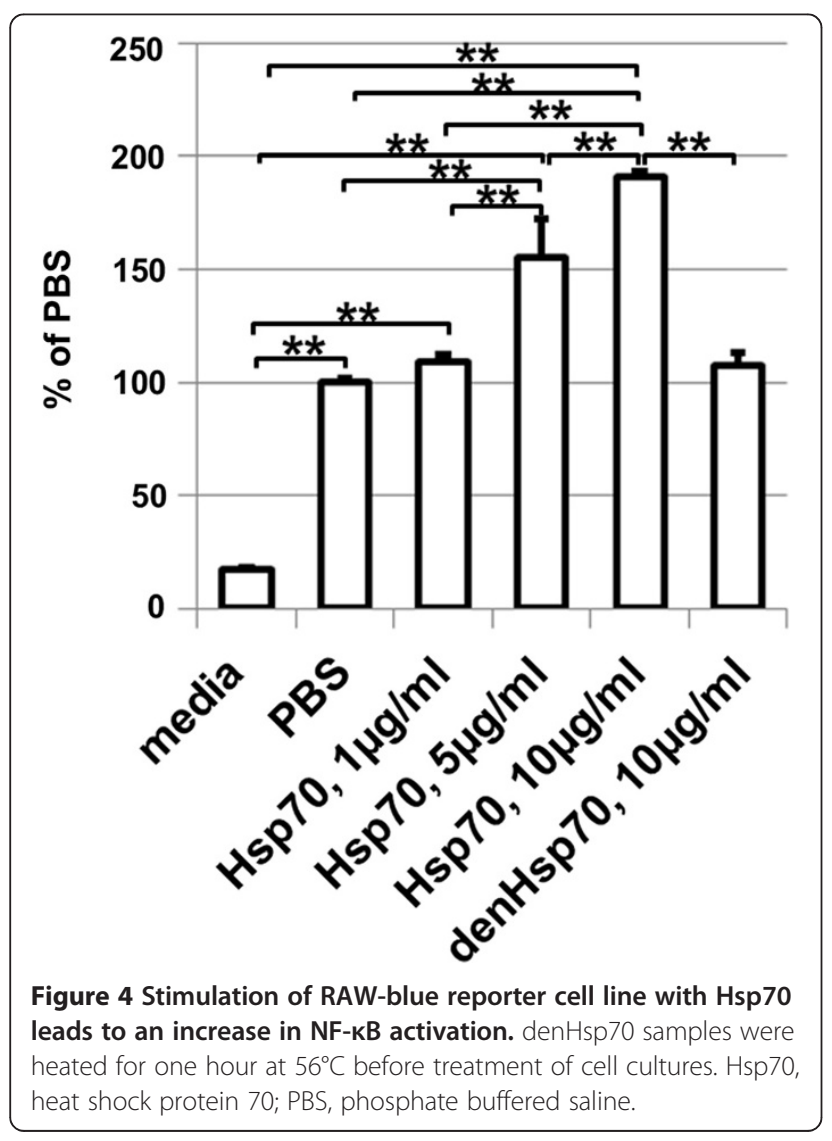

in glial cells isolated from Tlr4KO animals (Figure 5) as well as in glial cells treated with heat-inactivated Hsp70 (Figure 5). Next we asked the question of whether such low detected levels of endotoxins can alone initiate a proinflammatory response. To answer this question, we tested the pro-inflammatory activation of glial cells at different concentrations of LPS. Since we observed a similar proinflammatory response of astrocytes and microglial cells upon Hsp70 treatment, the experiments were carried out on primary astrocytes isolated from wild type animals. We found that $2.5 \mathrm{ng} / \mathrm{ml}$ of LPS mediated pro-inflammatory activation of astrocytes, while $250 \mathrm{pg} / \mathrm{ml}$ of LPS had no stimulatory effects upon astrocytes (Figure 6). Thus, detected low endotoxin levels either play no role or can only amplify Hsp70 pro-inflammatory effects.

To answer the question of whether the detected low endotoxin levels affect pro-inflammatory activity of Hsp70, we performed an additional series of experiments using PMB. The primary astrocytes were treated 24 hours with $5 \mu \mathrm{g} / \mathrm{ml}$ of Hsp70 containing $1.5 \mathrm{pg} / \mathrm{ml}$ of endotoxins, LPS $(2.5 \mathrm{ng} / \mathrm{ml})$ in the presence or absence of PMB (1 and $10 \mu \mathrm{g} / \mathrm{ml}$ ). The cells were lysed after 24 hours and transcriptional levels of cytokines and chemokines were analyzed using quantitative PCR. We also tested the Tnf level in the media of treated cells using a mouse Tnf-specific ELISA kit. We found that the pro-inflammatory response of LPS-treated astrocytes was significantly reduced by the addition of $1 \mu \mathrm{g} / \mathrm{ml}(0.7 \mu \mathrm{M})$ of PMB (Figure $7 \mathrm{~A})$. At the same time, Hsp70-treated astrocytes in the presence of $1 \mu \mathrm{g} / \mathrm{ml}(0.7 \mu \mathrm{M})$ of PMB did not reduce but rather increased expression of the cytokines and chemokines (Figure 7A). We also found that the level of Tnf in culture media from LPS/PMB-treated cells was significantly reduced, while the level of Tnf in culture media from Hsp70/PMB-treated cells was just slightly/insignificantly reduced (Figure 7B). However, treatment of cell cultures with $10 \mu \mathrm{g} / \mathrm{ml}(7 \mu \mathrm{M})$ of PMB significantly reduced expression levels of tested cytokines and chemokines in astrocytes mediated by Hsp70 and LPS (Figure 7A). Interestingly, we were still able to detect Tnf in media from PMB- $(10 \mu \mathrm{g} / \mathrm{ml}$ or $7 \mu \mathrm{M})$ and Hsp70-treated cells, while presence of Tnf in media from PMB- $(10 \mu \mathrm{g} / \mathrm{ml}$ or $7 \mu \mathrm{M})$ and LPS-treated cells was not detected (Figure 7B). It should be recalled that PMB inhibits PKC with an IC50 equal to 2-10 $\mu \mathrm{M}$ [23-25]. Thus, Hsp70-activated cells behave as if PMB inhibits only PKC and the presence of low levels of endotoxins does not play a role, while LPSactivated cells behave as if PMB inhibits LPS and PKC. It was shown previously that PKC activation is critical in LPS-mediated production of pro-inflammatory factors by macrophages [26]. To test the role of PKC in Hsp70dependent pro-inflammatory response, astrocytes were treated with Hsp70 in the presence or absence of PKC inhibitor (Gö6976, $10 \mathrm{nM}$ and $100 \mathrm{nM}$ ). After 24 hours, 


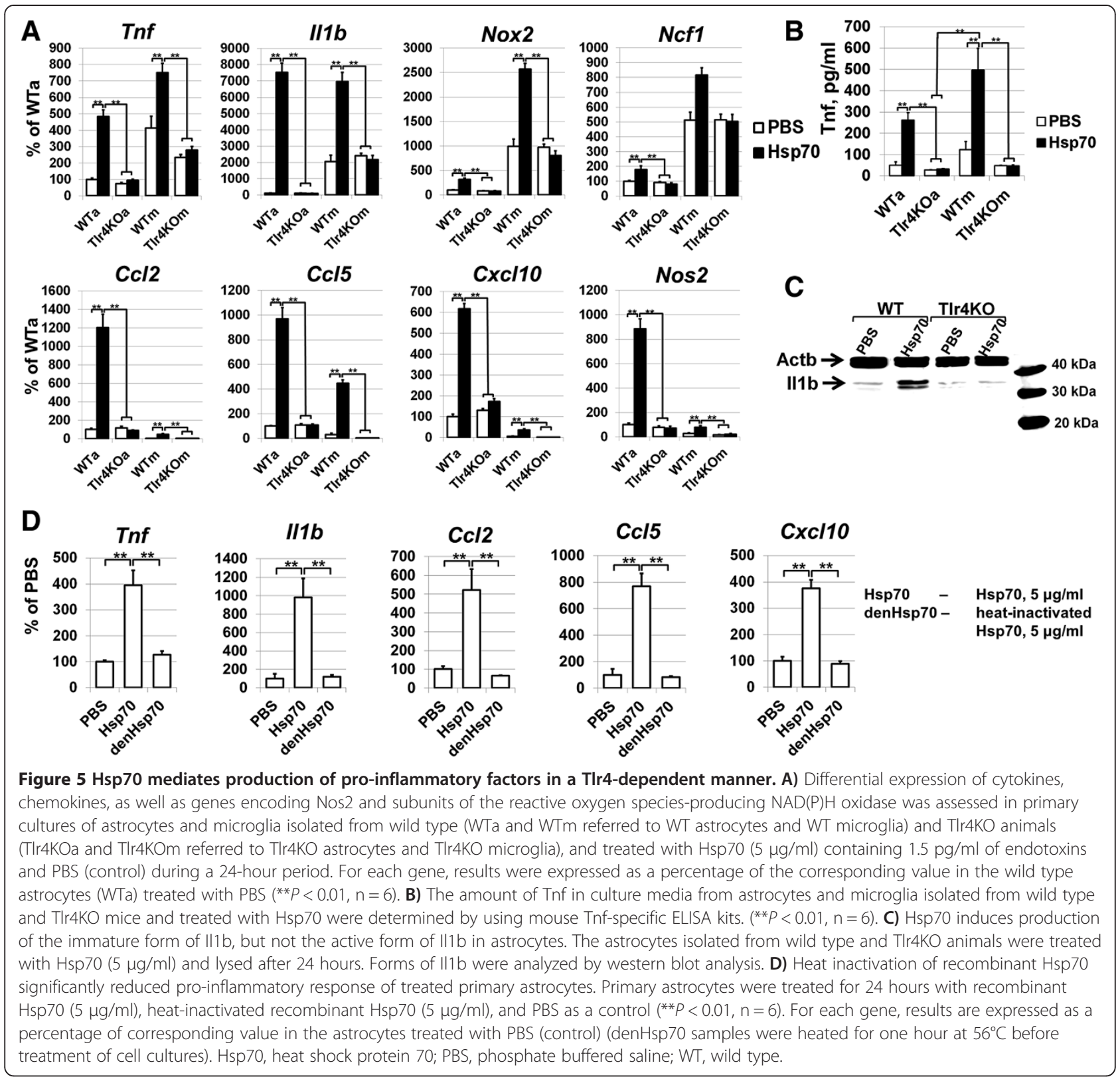

culture media was collected and the Tnf level was detected using the ELISA kit. We found that the level of Tnf was significantly reduced in Gö6976-treated cells (Figure 7C). Collectively, these data suggest that PKC is critical to mediate the Hsp70-dependent pro-inflammatory response. At the same time, the presence of low endotoxin levels in Hsp70 preparations is not critical in mediating the production of pro-inflammatory factors. Importantly, PMB in Hsp70-treated cultures behaves as a PKC inhibitor.

Extracellular Hsp70 mediates Tnf-dependent neuronal death Changes in the levels of intracellular and extracellular Hsp70 can produce different responses after IR injury: intracellular Hsp70 mediates neuroprotection after IR $[31,32]$, while our results indicate that extracellular Hsp70, providing that $\mathrm{PKC}$ is activated, should induce a strong neurotoxic pro-inflammatory response in tissue. Thus, interplay between pro-survival and death-promoting signaling cascades can continue until one eventually dominates and determines the cell's fate. We propose that a high level of extracellular Hsp70 released as a result of ischemic stress initiates a severe neurotoxic pro-inflammatory response, which far exceeds Hsp70 neuroprotective activity and finally mediates neuronal death. To test this hypothesis, we first determined the concentration of Hsp70, which can mediate RGC death in RGC/glia 

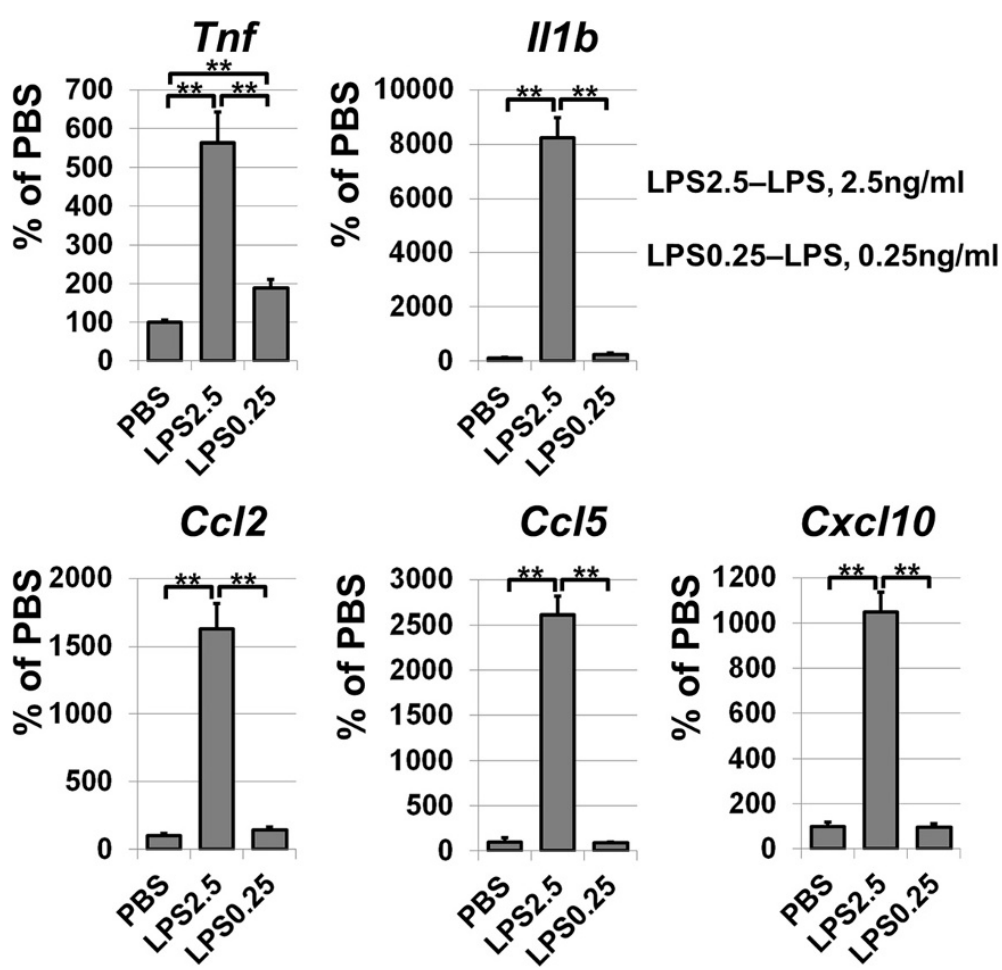

Figure 6 Astrocytes respond differently to varying concentrations of LPS. Stimulation of primary astrocytes with $2.5 \mathrm{ng} / \mathrm{ml}$ of LPS leads to increased expression of pro-inflammatory genes, while the pro-inflammatory response of primary astrocytes treated with $0.25 \mathrm{ng} / \mathrm{ml}$ was insignificant. Gene expression was assessed in primary astrocytes treated 24 hours with LPS and PBS (controls) by quantitative RT-PCR. For each gene, results were expressed as a percentage of the corresponding value in the astrocytes treated with PBS. LPS, lipopolysaccharides; PBS, phosphate buffered saline.

co-culture. Primary RGCs were plated on cover slips in a 24-well plate and glial cells (50\% primary astrocytes and $50 \%$ microglial cells) plated in culture inserts were placed into the culture wells containing RGCs prior to Hsp70 treatment. These co-cultures were treated with $5 \mu \mathrm{g} / \mathrm{ml}$ and $20 \mu \mathrm{g} / \mathrm{ml}$ of Hsp70. The level of RGC death was assessed after 24 hours. Quantification of RGC death showed significantly higher cell death in cultures treated with Hsp70 than with PBS (Figure 8A). However, when RGC loss was compared between cultures treated with 5 and $20 \mu \mathrm{g} / \mathrm{ml}$ of Hsp70, significant differences in neuronal viability became apparent. RGCs treated with $20 \mu \mathrm{g} / \mathrm{ml}$ of Hsp70 had lower numbers of RGC survival $(40 \pm 3 \%)$ than RGCs treated with $5 \mu \mathrm{g} / \mathrm{ml}$ of Hsp70 $(51 \pm 1 \%, P<0.05$, Figure 8A). To evaluate the contribution of PKC activity in the observed Hsp70-dependent RGC death, we used RGC/glia co-culture treated with $20 \mu \mathrm{g} / \mathrm{ml}$ of Hsp70 in the presence of $10 \mu \mathrm{g} / \mathrm{ml}(7 \mu \mathrm{M})$ of PMB. Co-cultures treated with Hsp70 only were used as controls. We found that RGC cultures in the presence of a PKC inhibitor were protected against treatment with Hsp70 and demonstrated a reduced level of RGC death (53 $\pm 1 \%$ vs $40 \pm 3 \%, P<0.05$ ) (Figure $8 \mathrm{~B}$ ). These in vitro data suggest that extracellular Hsp70 released as a result of ischemic stress can mediate neuronal death if there is PKC activity in glial cells. To verify the observed results in vivo, the left eyes of WT and Tlr4KO mice were intravitreally injected with Hsp70. The contralateral eyes were treated with a vehicle and used as controls. The retinas were collected seven days after treatment and whole retina flat-mounts were stained for the RGC marker beta III Tubulin to quantify the number of surviving RGCs in the GCL (Figure 8C). We observed that retinas from experimental eyes of WT mice had a significantly higher percentage of dead RGCs $(21 \pm 3 \%)$ than the Tlr4KO mice $(4 \pm 1 \%, P<0.01$, Figure $8 \mathrm{D})$. To evaluate the mechanism of Hsp70-mediated RGC death, we noted that treatment of glial cells with Hsp70 induced significant Tnf production (Figure 8E). It was shown previously that Tnf plays a largely deleterious role in retinal IR injury [33]. To study the role of Tnf in Hsp70-mediated RGC death, RGC/glia co-cultures were challenged with $20 \mu \mathrm{g} / \mathrm{ml}$ of $\mathrm{Hsp} 70$ in the presence or absence of XPro1595, a selective soluble Tnf blocker. Levels of RGC survival in these co-cultures were assessed 24 hours after treatment. We found that treatment with Hsp70 only decreased the number of live RGCs (40 $\pm 3 \%$ ), while the RGC death was reduced in the presence of XPro1595 $(64 \pm 5 \%, P<0.01)$ (Figure $8 \mathrm{~F}$ ). Thus, one way that extracellular Hsp70 can 


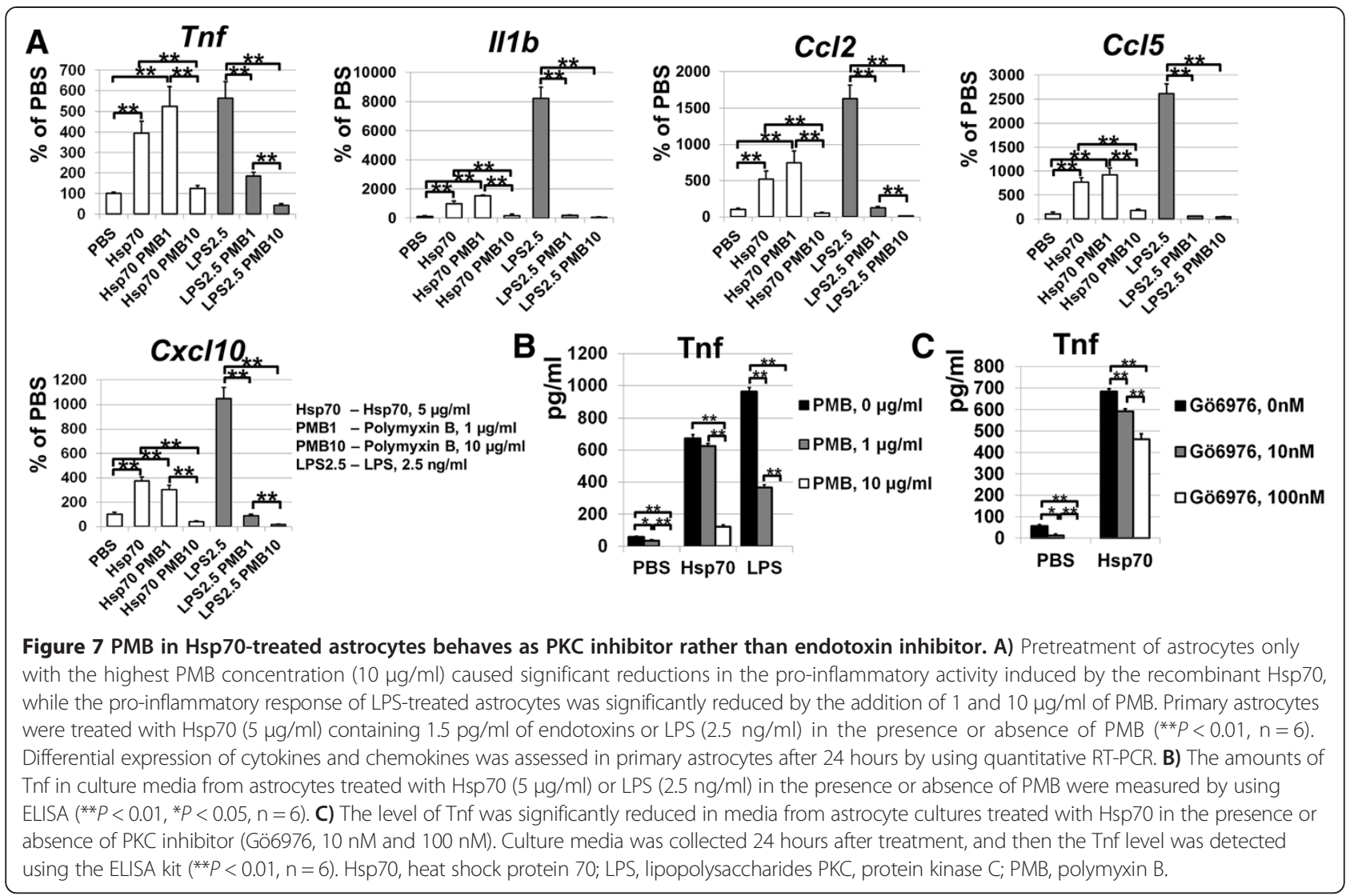

promote neuronal death is by mediating the production of cytotoxic levels of Tnf by glial cells.

Since Tlr4 signaling consists of two distinct signaling cascades, Myd88- and Trif/Ripk1-dependent [10,34,35], we evaluated the expression of Tlr4, Myd88, Trif and Ripk1 in primary glial cells isolated from WT and Tlr4KO animals and treated with $5 \mu \mathrm{g} / \mathrm{ml}$ of Hsp70 to identify cascades involved in Hsp70-dependent neurotoxicity. We found that the transcriptional levels of Tlr4 and Myd88 were increased in wild type astrocytes treated with Hsp70, but not in microglia (Figure 9A). We also found no significant changes in the expression of Trif and Ripk1 (Figure 9A). However, whereas astrocytes and microglia expressed only a low level of Trif, they exhibited significantly higher levels of Myd88 (Figure 9B). These data suggest that the role of the Myd88 signaling cascade may be more important in Hsp70-dependent proinflammatory activation of glial cells than the role of the Trif signaling cascade. To test this hypothesis, primary glial cells were isolated from WT, Tlr4, Myd88- and Trifdeficient animals, treated with Hsp70 as described above, and then the Tnf levels were measured in the media of these glial cells. We detected significantly reduced levels of Tnf in media of Hsp70-treated Tlr4, Myd88- and Trifdeficient glial cell cultures compared to glial cells isolated from WT animals (Figure 9C). However, the level of Tnf in media of Hsp70-treated Myd88KO glial cells was reduced significantly compared to TrifKO glial cells treated with Hsp70 (Figure 9C), which supports the hypothesis.

\section{Discussion}

Sterile inflammation, or innate immune response in the absence of live pathogens, is an unavoidable consequence of IR injury in the CNS, which jeopardizes the viability of the neurons at the site of injury [1-3]. It has been shown that IR-induced degenerative conditions can be significantly improved by modulating the activity of pro-inflammatory signaling cascades $[1,36]$. However, it would be more effective to eliminate the triggers of sterile inflammation rather than blocking their effector pathways. Many results obtained in vivo indicate that the triggers of sterile inflammation are DAMPs, which are released outside the cell following tissue injury, such as injury induced by IR, and the subsequent activation of pattern recognition receptors $[8,9]$. Tlr4 is a pattern recognition receptor that initiates an innate immune response in the presence of bacteria-derived endotoxins and DAMPs $[9,10]$. Importantly, the critical role of Tlr4 was shown in damage and sterile inflammation triggered by IR in the CNS $[11,12,37]$. However, in vitro studies suggest that DAMPs alone cannot activate Tlr4, and thus additional factors should be involved in the DAMP- 

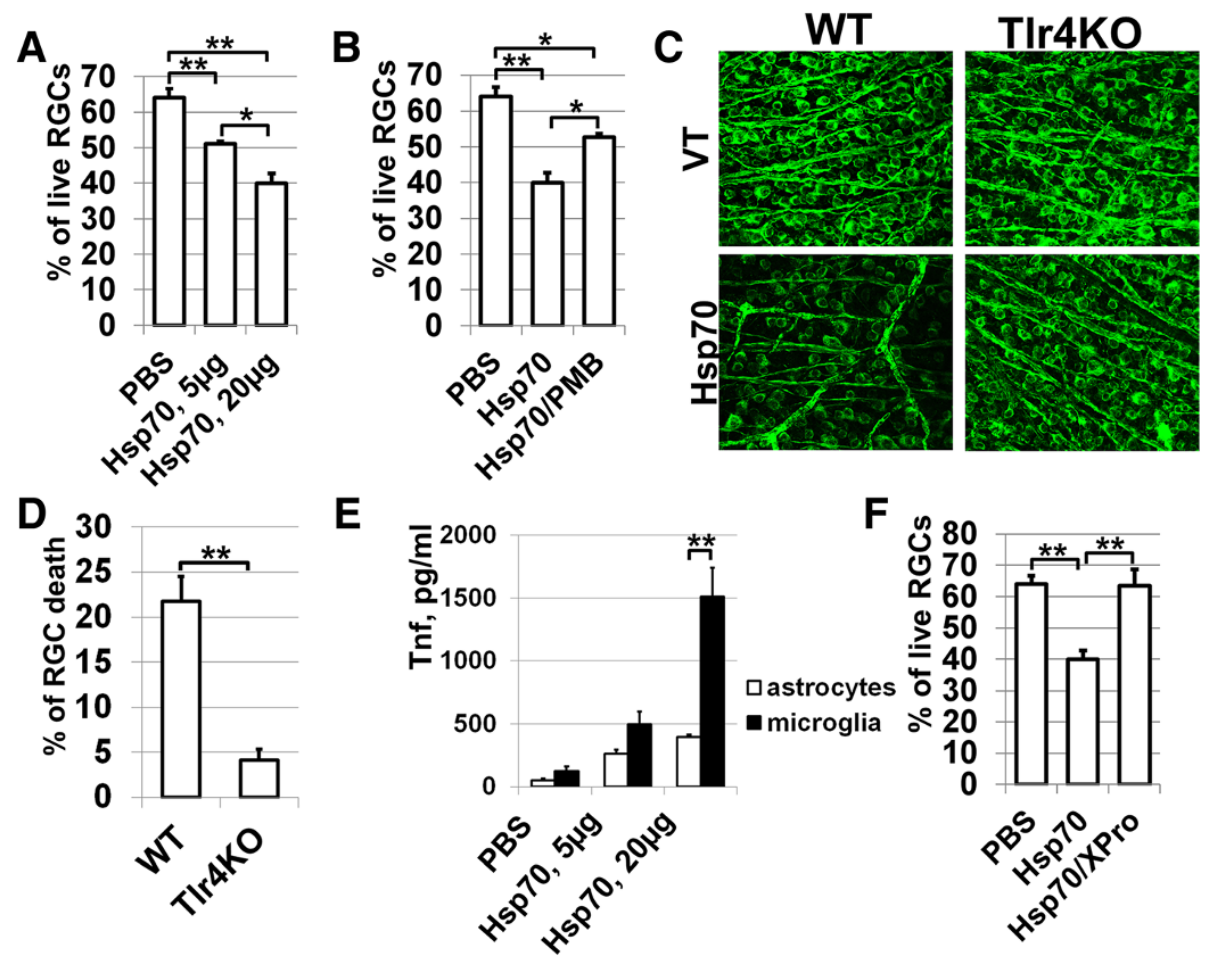

Figure 8 Extracellular Hsp70 promotes RGC death by mediating production of cytotoxic levels of Tnf by glial cells. A) Recombinant Hsp70 contributes to RGC death in vitro. RGC/glia co-cultures were treated 24 hours with 5 and $20 \mu \mathrm{g} / \mathrm{ml}$ of recombinant Hsp70, and RGC death was detected by using the Apoptosis Assay Kit \#2; (Invitrogen, United States). B) Inhibition of PKC activity in RGC/glia co-cultures with PMB helps to protect RGCs from neurotoxicity mediated by Hsp70. RGC/glia co-cultures were treated 24 hours with $20 \mu \mathrm{g} / \mathrm{ml}$ of Hsp70 in the presence of 10 $\mu \mathrm{g} / \mathrm{ml}$ of PMB or PBS (control) and then RGC death was detected. C) Representative confocal images of beta III Tubulin-labeled RGCs in the GCLs (green) of flat-mounted retinas of eyes intravitreally injected with $\mathrm{Hsp} 70(1 \mu \mathrm{g}$ per injection) and control eyes (vehicle treated; VT) were obtained seven days after treatment. D) The percent of RGC death in control and Hsp70-treated eyes of WT and Trr4KO animals (**P<0.01, n=6). E) Glial cells treated with Hsp70 produce sufficient amounts of Tnf to initiate neuronal death. F) Treatment with Hsp70 increased RGC death in the RGC/glia co-cultures, while treatment with Hsp70 in the presence of Tnf inhibitor (XPro1595) resulted in RGC protection. Hsp70, heat shock protein 70; PMB, polymyxin B, PKC, protein kinase C; RGC, retinal ganglion cells.

mediated pro-inflammatory response in tissue. In our study, we focused on extracellular Hsp70, a prototypic DAMP molecule and ligand of Tlr4, because it was released at high levels after IR in the retina. We tested whether the presence of low endotoxin levels (subclinical level, not leading to pro-inflammatory response) in ischemic tissue or PKC activity were involved in Hsp70mediated pro-inflammatory neurotoxicity. Since activation of glial cells was shown to occur temporally before leukocyte infiltration in ischemic tissue, we used primary astrocyte and microglia cell cultures in our study. We found that extracellular Hsp70 activates the Tlr4 signaling cascade in glial cells that initiate the production of neurotoxic factors. PKC activity was critical to initiate the Hsp70-dependent pro-inflammatory response. Meanwhile, the low endotoxin levels were not involved in Hsp70mediated pro-inflammatory activity.

The concept that endotoxins can be involved in DAMPmediated pro-inflammatory activity became evident when we noted that: 1) the presence of low endotoxin levels was shown in human and animal tissues [18-21,38]; and 2) endotoxins, even in small amounts, act in synergy and amplify the DAMP-mediated pro-inflammatory response $[9,15-17,39]$. It was suggested that the increased endotoxin levels in tissues might be a result of endotoxin translocation derived from the resident bacteria in the gastrointestinal tract [40-42]. However, detected endotoxin levels were too low to have any pathological significance in healthy tissue. At the same time, the low endotoxin levels dramatically sensitize the immature brain to injury and induce cerebral infarction in response to short periods of hypoxia-ischemia [43]. In addition, an endotoxin inhibitor can block heat exposure-induced expression of brain cytokines [18]. Thus, DAMPs released as a result of pathological conditions, such as IR, combined with a low-dose endotoxin in the tissue could initiate a pro-inflammatory response that promotes cell death and tissue damage. Since it was shown in some studies that pure (endotoxin free) DAMPs could not mediate a pro-inflammatory response, the concept received our considerable attention. 


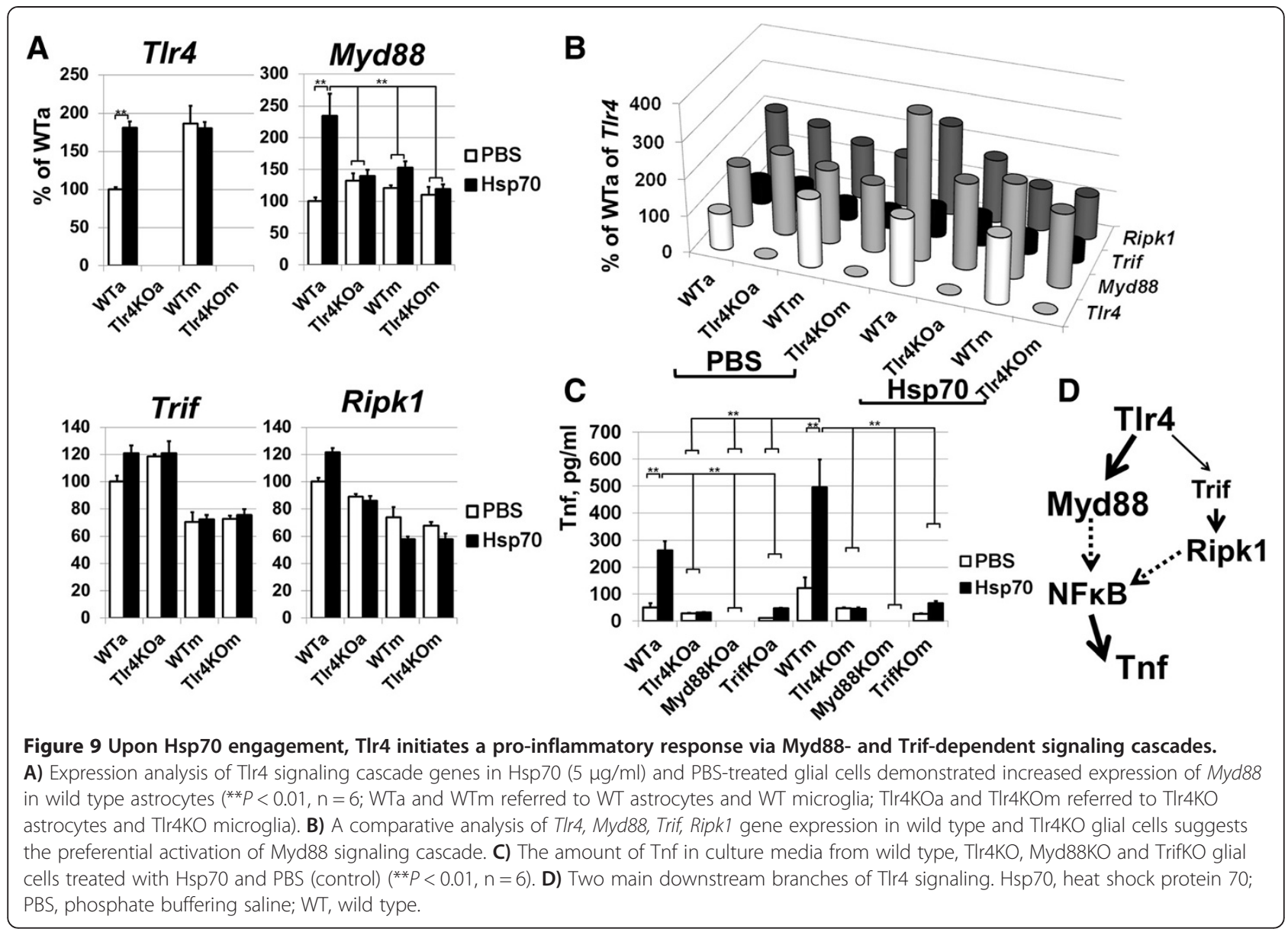

Like many others, we used the endotoxin inhibitor, PMB, in our study [22]. We found significant neuroprotection and a reduced pro-inflammatory response in ischemic retinas as a result of PMB treatment. However, we did not detect any endotoxin presence in the studied tissues. We also noted that in the cited papers, endotoxin levels were within the sensitivity range of the assay used. In addition, Rivera et al. [21] detected endotoxins in the portal vein but not the vena cava, showing endotoxins to be present in blood coming from the gastrointestinal tract to the liver, and then being detoxified in the liver before being distributed to the rest of the body. It is therefore hard to conclude whether the neuroprotective effect of PMB in vivo is due to inhibition of undetectable levels of endotoxin, or other effects that are unrelated to endotoxins. PMB is also a PKC inhibitor [23-25], and thus, the in vivo protective effects could be due to inhibition of PKC. To test this hypothesis we treated the animals with a known PKC inhibitor (Gö6976) and found significant neuroprotection. Therefore, the neuroprotective effect in PMB-treated ischemic retinas should be due to PKC inhibition rather than endotoxin inhibition.
The universally expressed PKC family in vertebrate tissues is involved in many signaling cascades, including the innate immune response [26,44]. PKC isozymes modify other proteins by chemically adding phosphate groups to them from a nucleoside triphosphate (ATP) and are classified as conventional, novel and atypical $[26,44,45]$. Conventional PKC isozymes are $\mathrm{Ca}^{2+}$-dependent, while novel and atypical isozymes do not require $\mathrm{Ca}^{2+}$ for their activation. In our study, we used PKC inhibitors, which inhibit predominantly conventional PKC isozymes. Many PKC isozymes, including conventional ones, were identified in the retina and were activated as a result of IR [46]. Since: 1) PKC family is directly involved in the Tlr4mediated innate immune response [26]; 2) PKC inhibitors reduce retinal damage and inflammation and; 3 ) release of Hsp70, a known DAMP and ligand of Tlr4 [3,9], was observed after retinal IR, we hypothesized that Hsp70 released as a result of IR activates Tlr4 and initiates a neurotoxic pro-inflammatory response in the presence of PKC activity. To test this hypothesis, we turned to cell cultures. We used Hsp70 containing low-dose endotoxin. However, since endotoxins were still present in Hsp70 preparations, we have taken all precautions to properly 


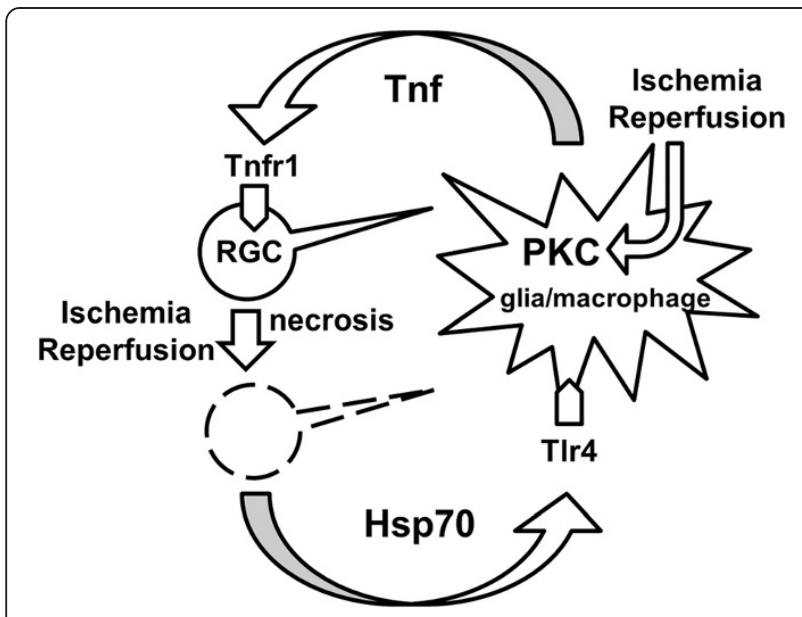

Figure 10 Proposed mechanism of extracellular Hsp70-mediated neurotoxic pro-inflammatory response in tissue after IR.

The initial ischemic stress followed by reperfusion leads to the cell injury (necrosis) and the release of Hsp70. That same ischemic stress (increase in intracellular $\mathrm{Ca}^{2+}$ ) and reperfusion (increase in ATP (adenosine triphosphate)) mediate PKC activation. These two events are the necessary and sufficient conditions for activation of TIr4 signaling and production of neurotoxic levels of pro-inflammatory factors such as Tnf. This pro-inflammatory response can trigger further tissue damage leading to increasing levels of extracellular Hsp70. Thus, a cycle may be repeated many times, which can result in significant tissue damage after IR. ATP, Hsp70, heat shock protein 70; IR, ischemic reperfusion; PKC, protein kinase $C$.

interpret the data. We found that the presence of native Hsp70 was critical in Tlr4-dependent innate immune response and PKC inhibitors reduced Hsp70-mediated production of pro-inflammatory factors. Importantly, LPS-activated cells behaved as if PMB inhibits LPS and PKC, while Hsp70-activated cells behaved as if PMB inhibits only PKC and the presence of low endotoxin levels has no role to play. Thus, these data suggest that PKC activity, but not low-dose endotoxin presence, is critical to mediate an Hsp70-dependent pro-inflammatory response.

Taken together, we can suggest that PKC activation as a result of ischemia (increase in intracellular $\mathrm{Ca}^{2+}$ ) reperfusion (increase ATP) $[46,47]$ and increase of extracellular Hsp70 as a result of tissue damage promotes the activation of Tlr4 signaling that initiates a neurotoxic pro-inflammatory response (Figure 10). It is known that Myd88 and Trif adaptor proteins modulate the Tlr4 signaling pathway $[10,35]$. Our data suggests that the Myd88 signaling cascade is probably more important in Hsp70-dependent pro-inflammatory activation of glial cells than the Trif signaling cascade. We also demonstrated that Hsp70 mediates activation of NF- $\kappa B$ transcription factor, which initiates transcription of genes coding proteins such as cytokines, chemokines, and ROS producing enzymes, which can mediate cell death and promote tissue damage [48]. We have found that Hsp70treated astrocytes are a primary source of chemokines, and thus can facilitate leukocyte infiltration in the ischemic tissue. At the same time, Hsp70-activated microglia may be responsible mainly for ROS production. Both types of glial cells release Tnf and produce the immature form of Illb in a Tlr4-dependent manner in the presence of Hsp70. Collectively, all these factors can mediate neuronal toxicity, which was observed previously $[28,33,49]$. Our in vivo and in vitro data indicate that one way that extracellular Hsp70 can promote neuronal death is by mediating production of cytotoxic levels of Tnf by glial cells. Importantly, in contrast to the data above, intracellular Hsp70 assists protein-folding processes in all cells, and helps to protect neurons from ischemic stress [31,32]. However, the results presented in this study suggest that high levels of extracellular Hsp70 released as a result of ischemic stress in tissue can initiate a strong neurotoxic pro-inflammatory response, which far exceeds the neuroprotective activity of Hsp70.

\section{Conclusions}

In this study we describe for the first time the molecular mechanism of extracellular Hsp70 pro-inflammatory activity in the retina after IR. Our findings indicate that Hsp70 can mediate Tlr4-dependent innate immune response only if PKC activity is present. This data is of great significance because lately there have been doubts regarding the ability of pure DAMPs (extracellular Hsp70 is one of them) to initiate an innate immune response. The mechanism described here can offer insights on the ability of many other DAMPs to mediate innate immune response in ischemic tissue, and may be helpful for the development of new drugs against IR injury.

\section{Abbreviations}

CNS: central nervous system; DAMPs: damage-associated molecular patterns; GCL: ganglion cell layer; Hsp70: heat shock protein 70; I1 b: interleukin-1 $\beta$; IOP: intraocular pressure; IP: intraperitoneally; IR: ischemic-reperfusion; Myd88: myeloid differentiation primary response 88 ; NeuN: neuronal nuclei; NF-KB: nuclear factor kappa B; PKC: protein kinase C; PMB: polymyxin B; RGC: retinal ganglion cell; Tlr:: toll-like receptor; Tnf: tumor necrosis factor; Trif: TIR-domain-containing adapter-inducing interferon- $\beta$; VH: vitreous humor; WT: wild type.

\section{Competing interests}

The authors declare they have no competing interests.

\section{Authors' contributions}

$\mathrm{DI}$ and GD conceived the study and participated in its design and coordination. DI, GD, ARCS and AMS analyzed the data, and drafted the manuscript. GD was responsible for induction of $I R$, retina isolations, immunohistochemistry. XD and ARCS carried out immunohistochemistry, and RGC quantification. DI and AMS carried out quantitative RT-PCR. All authors read and approved the final manuscript.

\section{Acknowledgements}

The study was supported in part by National Eye Institute/National Institutes of Health (NIH) Grant R01 EY022348 (DI), James and Esther King Biomedical Research Program Bridge Grant 3 KB01-50988 (DI), NIH Center Core Grant P30EY014801, Research to Prevent Blindness Unrestricted Grant, Department of Defense (DOD- Grant\#W81XWH-09-1-0675 and Grant\# W81XWH-13-1-0048 ONOVA). The content is solely the responsibility of the authors and does not 
necessarily represent the official views of the National Eye Institute or the National Institutes of Health. We thank David E. Szymkowski (Xencor, Inc.) for providing XPro1595 compound. The authors thank Eleut Hernandez, Dagmara Danek and Gabriel Gaidosh for their expert assistance.

\section{Author details}

'Bascom Palmer Eye Institute, Department of Ophthalmology, University of Miami Miller School of Medicine, 1638 NW 10th Ave, Miami, FL 33136, USA.

${ }^{2}$ Sheila and David Fuente Program in Cancer Biology, University of Miami Miller School of Medicine, 1550 NW 10th Ave, Miami, FL 33136, USA. ${ }^{3}$ Department of Microbiology and Immunology, University of Miami Miller School of Medicine, 1600 NW 10th Ave, Miami, FL 33136, USA.

Received: 7 January 2014 Accepted: 4 April 2014

Published: 23 April 2014

\section{References}

1. Shah IM, Macrae IM, Di Napoli M: Neuroinflammation and neuroprotective strategies in acute ischaemic stroke - from bench to bedside. Curr $\mathrm{Mol}$ Med 2009, 9:336-354.

2. Eltzschig HK, Eckle T: Ischemia and reperfusion-from mechanism to translation. Nat Med 2011, 17:1391-1401.

3. Chen GY, Nunez G: Sterile inflammation: sensing and reacting to damage. Nat Rev Immunol 2010, 10:826-837.

4. Fujita R, Ueda M, Fujiwara K, Ueda H: Prothymosin-alpha plays a defensive role in retinal ischemia through necrosis and apoptosis inhibition. Cell Death Differ 2009, 16:349-358.

5. Dvoriantchikova G, Barakat DJ, Hernandez E, Shestopalov VI, Ivanov D: Liposome-delivered ATP effectively protects the retina against ischemiareperfusion injury. Mol Vis 2010, 16:2882-2890.

6. Muhammad S, Barakat W, Stoyanov S, Murikinati S, Yang H, Tracey KJ, Bendszus M, Rossetti G, Nawroth PP, Bierhaus A, Schwaninger M: The HMGB1 receptor RAGE mediates ischemic brain damage. J Neurosci 2008, 28:12023-12031.

7. ladecola C, Anrather J: The immunology of stroke: from mechanisms to translation. Nat Med 2011, 17:796-808.

8. Dvoriantchikova G, Hernandez E, Grant J, Santos AR, Yang H, Ivanov D: The high-mobility group box-1 nuclear factor mediates retinal injury after ischemia reperfusion. Invest Ophthalmol Vis Sci 2011, 52:7187-7194.

9. Piccinini AM, Midwood KS: DAMPening inflammation by modulating TLR signalling. Mediators Inflamm 2010, 2010:672395.

10. Janeway CA Jr, Medzhitov R: Innate immune recognition. Annu Rev Immunol 2002, 20:197-216.

11. Dvoriantchikova G, Barakat DJ, Hernandez E, Shestopalov VI, Ivanov D: Toll-like receptor 4 contributes to retinal ischemia/reperfusion injury. Mol Vis 2010, 16:1907-1912.

12. Caso JR, Pradillo JM, Hurtado O, Lorenzo P, Moro MA, Lizasoain I: Toll-like receptor 4 is involved in brain damage and inflammation after experimental stroke. Circulation 2007, 115:1599-1608.

13. Yang $\mathrm{H}$, Hreggvidsdottir HS, Palmblad K, Wang H, Ochani M, Li J, Lu B, Chavan S, Rosas-Ballina M, Al-Abed Y, Akira S, Bierhaus A, Erlandsson-Harris $\mathrm{H}$, Andersson U, Tracey KJ: A critical cysteine is required for HMGB1 binding to Toll-like receptor 4 and activation of macrophage cytokine release. Proc Natl Acad Sci U S A 2010, 107:11942-11947.

14. Asea A, Kraeft SK, Kurt-Jones EA, Stevenson MA, Chen LB, Finberg RW, Koo GC, Calderwood SK: HSP70 stimulates cytokine production through a CD14-dependant pathway, demonstrating its dual role as a chaperone and cytokine. Nat Med 2000, 6:435-442.

15. Broere $F$, van der Zee $R$, van Eden W: Heat shock proteins are no DAMPs, rather 'DAMPERs'. Nat Rev Immunol 2011, 11:565.

16. Gao B, Tsan MF: Endotoxin contamination in recombinant human heat shock protein $70(\mathrm{Hsp} 70)$ preparation is responsible for the induction of tumor necrosis factor alpha release by murine macrophages. $J$ Biol Chem 2003, 278:174-179.

17. Bianchi ME: DAMPs, PAMPs and alarmins: all we need to know about danger. J Leukoc Biol 2007, 81:1-5.

18. Katafuchi T, Takaki A, Take S, Kondo T, Yoshimura M: Endotoxin inhibitor blocks heat exposure-induced expression of brain cytokine mRNA in aged rats. Brain Res Mol Brain Res 2003, 118:24-32.
19. Crawley BA, Morris JA, Drucker DB, Barson AJ, Morris J, Knox WF, Oppenheim BA: Endotoxin in blood and tissue in the sudden infant death syndrome. FEMS Immunol Med Microbiol 1999, 25:131-135.

20. Nalepka JL, Greenfield EM: Detection of bacterial endotoxin in human tissues. Biotechniques 2004, 37:413-417.

21. Rivera CA, Tcharmtchi MH, Mendoza L, Smith CW: Endotoxemia and hepatic injury in a rodent model of hindlimb unloading. $J$ Appl Physiol 2003, 95:1656-1663.

22. Cooperstock MS: Inactivation of endotoxin by polymyxin B. Antimicrob Agents Chemother 1974, 6:422-425.

23. Pugazhenthi S, Mantha SV, Khandelwal RL: Inhibitory effect of $\mathrm{H}-7, \mathrm{H}-8$ and polymyxin B on liver protein kinase C-induced phosphorylation of endogenous substrates. Biochem Int 1990, 20:941-948.

24. Raynor RL, Zheng B, Kuo JF: Membrane interactions of amphiphilic polypeptides mastoparan, melittin, polymyxin $B$, and cardiotoxin. Differential inhibition of protein kinase C, Ca2+/calmodulin-dependent protein kinase II and synaptosomal membrane $\mathrm{Na}, \mathrm{K}-\mathrm{ATPase}$, and $\mathrm{Na}+$ pump and differentiation of HL60 cells. J Biol Chem 1991, 266:2753-2758.

25. Allgaier $C$, Hertting $G$ : Polymyxin $B$, a selective inhibitor of protein kinase $C$, diminishes the release of noradrenaline and the enhancement of release caused by phorbol 12,13-butyrate. Naunyn Schmiedebergs Arch Pharmacol 1986, 334:218-221.

26. Loegering DJ, Lennartz MR: Protein kinase $C$ and toll-like receptor signaling. Enzyme Res 2011, 2011:537821.

27. Dvoriantchikova G, Grant J, Santos AR, Hernandez E, Ivanov D: Neuronal $\mathrm{NAD}(\mathrm{P}) \mathrm{H}$ oxidases contribute to ROS production and mediate RGC death after ischemia. Invest Ophthalmol Vis Sci 2012, 53:2823-2830.

28. Barakat DJ, Dvoriantchikova G, Ivanov D, Shestopalov VI: Astroglial NFkappaB mediates oxidative stress by regulation of NADPH oxidase in a model of retinal ischemia reperfusion injury. J Neurochem 2012, 120:586-597.

29. Remtulla S, Hallett PE: A schematic eye for the mouse, and comparisons with the rat. Vision Res 1985, 25:21-31.

30. Lafuente MP, Villegas-Perez MP, Selles-Navarro I, Mayor-Torroglosa S, Miralles de Imperial J, Vidal-Sanz M: Retinal ganglion cell death after acute retinal ischemia is an ongoing process whose severity and duration depends on the duration of the insult. Neuroscience 2002, 109:157-168.

31. Giffard RG, Xu L, Zhao H, Carrico W, Ouyang Y, Qiao Y, Sapolsky R, Steinberg $\mathrm{G}, \mathrm{Hu}$ B, Yenari MA: Chaperones, protein aggregation, and brain protection from hypoxic/ischemic injury. J Exp Biol 2004, 207:3213-3220.

32. Tsuchiya D, Hong S, Matsumori Y, Kayama T, Swanson RA, Dillman WH, Liu J, Panter SS, Weinstein PR: Overexpression of rat heat shock protein 70 reduces neuronal injury after transient focal ischemia, transient global ischemia, or kainic acid-induced seizures. Neurosurgery 2003, 53:1179-1188

33. Berger S, Savitz SI, Nijhawan S, Singh M, David J, Rosenbaum PS, Rosenbaum DM: Deleterious role of TNF-alpha in retinal ischemiareperfusion injury. Invest Ophthalmol Vis Sci 2008, 49:3605-3610.

34. Kawai T, Akira S: The role of pattern-recognition receptors in innate immunity: update on Toll-like receptors. Nat Immunol 2010, 11:373-384.

35. Takeda K, Akira S: Toll-like receptors in innate immunity. Int Immunol 2005, $17: 1-14$

36. Wang $X$ : Investigational anti-inflammatory agents for the treatment of ischaemic brain injury. Expert Opin Investig Drugs 2005, 14:393-409.

37. Arumugam TV, Okun E, Tang SC, Thundyil J, Taylor SM, Woodruff TM: Tolllike receptors in ischemia-reperfusion injury. Shock 2009, 32:4-16.

38. Brun P, Castagliuolo I, Di Leo V, Buda A, Pinzani M, Palu G, Martines D: Increased intestinal permeability in obese mice: new evidence in the pathogenesis of nonalcoholic steatohepatitis. Am J Physiol Gastrointest Liver Physiol 2007, 292:G518-G525.

39. Bianchi ME: HMGB1 loves company. J Leukoc Biol 2009, 86:573-576.

40. Deitch EA, Bridges RM: Effect of stress and trauma on bacterial translocation from the gut. J Surg Res 1987, 42:536-542.

41. Anderlik P, Szeri I, Banos Z, Barna Z: Bacterial translocation after cold stress in young and old mice. Acta Microbiol Hung 1990, 37:289-294.

42. Jiang J, Bahrami S, Leichtfried G, Redl H, Ohlinger W, Schlag G: Kinetics of endotoxin and tumor necrosis factor appearance in portal and systemic circulation after hemorrhagic shock in rats. Ann Surg 1995, 221:100-106.

43. Eklind S, Mallard C, Leverin AL, Gilland E, Blomgren K, Mattsby-Baltzer I, Hagberg $\mathrm{H}$ : Bacterial endotoxin sensitizes the immature brain to hypoxic-ischaemic injury. Eur J Neurosci 2001, 13:1101-1106. 
44. Spitaler M, Cantrell DA: Protein kinase C and beyond. Nat Immunol 2004, 5:785-790.

45. Gutcher I, Webb PR, Anderson NG: The isoform-specific regulation of apoptosis by protein kinase C. Cell Mol Life Sci 2003, 60:1061-1070.

46. Wood JP, McCord RJ, Osborne NN: Retinal protein kinase C. Neurochem Int 1997, 30:119-136

47. Osborne NN, Casson RJ, Wood JP, Chidlow G, Graham M, Melena J: Retinal ischemia: mechanisms of damage and potential therapeutic strategies. Prog Retin Eye Res 2004, 23:91-147.

48. Dvoriantchikova G, Barakat D, Brambilla R, Agudelo C, Hernandez E, Bethea JR, Shestopalov VI, Ivanov D: Inactivation of astroglial NF-kappa B promotes survival of retinal neurons following ischemic injury. Eur J Neurosci 2009, 30:175-185.

49. Yoneda S, Tanihara H, Kido N, Honda Y, Goto W, Hara H, Miyawaki N: Interleukin-1 beta mediates ischemic injury in the rat retina. Exp Eye Res 2001, 73:661-667.

doi:10.1186/1742-2094-11-81

Cite this article as: Dvoriantchikova et al:: Putative role of protein kinase

$C$ in neurotoxic inflammation mediated by extracellular heat shock protein 70 after ischemia-reperfusion. Journal of Neuroinflammation 2014 11:81.

\section{Submit your next manuscript to BioMed Central and take full advantage of:}

- Convenient online submission

- Thorough peer review

- No space constraints or color figure charges

- Immediate publication on acceptance

- Inclusion in PubMed, CAS, Scopus and Google Scholar

- Research which is freely available for redistribution 